Article

\title{
Coagulation Parameters: An Efficient Measure for Predicting the Prognosis and Clinical Management of Patients with COVID-19
}

\author{
Manuel Quintana-Díaz ${ }^{1}$, Eva María Andrés-Esteban ${ }^{2, *}$, Karen Lizzette Ramírez-Cervantes ${ }^{2}{ }^{\circledR}$, \\ Bárbara Olivan-Blázquez $^{3}\left(\mathbb{D}\right.$, Raúl Juárez-Vela ${ }^{2,4, *}$ and Vicente Gea-Caballero ${ }^{5}$ (D) \\ 1 Intensive Care Unit, La Paz University Hospital, Research Group BPM, Idi-Paz Research Institute, \\ Paseo de la Castellana, 261, 28046 Madrid, Spain; mquintanadiaz@gmail.com \\ 2 Research Group BPM, Idi-Paz Research Institute, University Rey Juan Carlos, Calle de Pedro Rico, 6 , \\ 28029 Madrid, Spain; karenlizzetteramirez@gmail.com \\ 3 Research Unit in Primary Care, IIS Aragón, Avda, University of Zaragoza, San Juan Bosco, 13, \\ 50009 Zaragoza, Spain; barbaraolivan@gmail.com \\ 4 Faculty of Health Sciences, La Rioja University, Edificio de Rectorado, Av. de la Paz, 93, 26006 Logroño, Spain \\ 5 Nursing School La Fe, Adscript Center of University of Valencia, Research Group GREIACC, \\ Health Research Institute La Fe, Avda, Fernando Abril Martorell 106, Pabellón Docente Torre H, \\ 46006 Valencia, Spain; gea_vic@gva.es \\ * Correspondence: e.andres@live.com (E.M.A.-E.); raul.juarez@unirioja.es (R.J.-V.)
}

Received: 11 September 2020; Accepted: 26 October 2020; Published: 28 October 2020

\begin{abstract}
Background. COVID-19 is an ongoing global pandemic. Since the detection of the first cases of coronavirus disease 2019 (COVID-19) in Wuhan, China, the current pandemic has affected more than 25.3 million people worldwide. The aim of this study was to evaluate the relationship between coagulation abnormalities and prognosis in a cohort of patients with COVID-19. Methods. We performed a retrospective cohort study of 3581 patients admitted to Hospital La Paz (Madrid, Spain) due to respiratory infection by severe acute respiratory syndrome coronavirus from the beginning of the current pandemic to 15 July 2020 . Results. Of the 3581 study patients, $48.94 \%$ were men, and $19.80 \%$ were healthcare workers. The median age was 62 years. Compared with the survivors, the non-survivors had lower prothrombin activity (82.5 (Interquartile range-IQR, 67-95) vs. 95.25 (IQR, 87-104) for non-survivors and survivors, respectively; $p<0.001$ ), higher fibrinogen levels (748.5-IQR, 557-960) vs. 572.75 (IQR, 417-758; $p<0.001$ ), and notably higher D-dimer levels (2329-IQR, 1086.12-5670.40) vs. 635.5 (IQR, 325.5-1194.8); $p<0.001$ ). Conclusions. The evaluation of coagulation parameters could be an efficient measure for predicting the prognosis and improving the clinical management of patients with COVID-19.
\end{abstract}

Keywords: coronavirus; COVID-19; SARS-CoV-2; coagulation

\section{Introduction}

Since the detection of the first cases of coronavirus disease 2019 (COVID-19) in Wuhan, China, the current pandemic has affected more than 25.3 million people worldwide, reaching high rates of mortality in high-risk individuals and presenting multiple manifestations in addition to pulmonary complications [1-3]. Coagulation abnormalities are typical findings in patients with COVID-19 and are associated with poorer prognoses and survival. High D-dimer levels, for example, are consistently associated with poor outcomes and death [4]. Similarly, a significant prothrombin time (PT) prolongation has been observed in severe cases and is more evident among non-survivors [5]. During the acute response of the infection, fibrinogen levels can reach upper limits, which can persist as the disease 
progresses; however, a sudden decrease in these levels has been observed shortly before death in a patient cohort with novel coronavirus pneumonia $[5,6]$. The hematological abnormalities observed in COVID-19 patients suggest a procoagulant state that has been linked to both arterial and venous thrombosis, which is more frequently reported in severe cases [7-9]. A study conducted in China found that among 138 cases of COVID-19, venous thromboembolic events (VTE) occurred in 2.9\%; however, in a smaller sample of critically ill patients admitted to intensive care units (ICUs), the VTE rate was $20 \%$ [10]. In France, pulmonary embolism (PE) rates in a single-center have been compared between ICU admissions for COVID-19 in 2020 and the general ICU population of the previous year, finding rates of $20.6 \%$ and $6.1 \%$, respectively [11]. Coagulopathy has been reported in up to $50 \%$ of patients with severe COVID-19 manifestations, in whom disseminated intravascular coagulopathy (DIC) has been found in more than $70 \%$ of the cases [8]. However, the coagulation profile usually observed in DIC might not be consistent with the findings in COVID-19 patients, and the development mechanisms might differ [9]. In addition, a number of abnormal coagulation parameters, such as elevated D-dimer levels, have been found to be an independent risk factor for mortality for these patients [4].

Despite the numerous ongoing studies evaluating the underlying physiopathology of coagulopathy in COVID-19, it remains poorly understood $[12,13]$. Prophylactic therapy has been recommended for hospitalized patients because it appears to reduce mortality due to coagulation disorders [14]. In some cases, however, PE and venous VTE have been diagnosed in COVID-19 patients regardless of the administration of standard pharmacological thromboprophylaxis $[11,15,16]$. Anticoagulation might, therefore, be insufficient for certain circumstances, and alternative or additional therapies might be required.

Given that abnormal coagulation parameters might be associated with poor prognoses, monitoring hemostatic markers in all patients with COVID-19 might be advisable. The aim of this study was, therefore, to evaluate the relationship between coagulation abnormalities and prognosis in a cohort of hospitalized COVID-19 patients in a high-level hospital in Madrid, Spain.

We presented a retrospective analysis of 3581 patients to establish the relationship between coagulation parameters and poor outcomes in COVID-19 patients.

\section{Methods}

\subsection{Study Design and Participants}

We conducted a retrospective cohort study and analyzed the sociodemographic data, clinical status, laboratory test results, and medical management information during the hospitalization of 3581 patients admitted to La Paz University Hospital (Madrid, Spain) due to respiratory infection by severe acute respiratory syndrome coronavirus from the start of the current pandemic to the 15th of July 2020. The laboratory test results were obtained during the patients' hospitalization and are presented as medians for all data collected during all processes and in all units. For the inclusion criteria, we analyzed all patients with COVID-19 based on the detection of SARS-CoV-2 RNA in throat swab specimens. The study was conducted in accordance with the principles of the Declaration of Helsinki, the Harmonized Tripartite Guidelines for Good Clinical Practice of the International Conference on Harmonization, the guidelines for Good Epidemiological Practice, and the European and Spanish regulations for the protection of personal data. The study was approved by the Clinical Research Ethics Committee of the La Paz University Hospital (HULP code: PI-4155).

\subsubsection{Main Variables}

The main study variables were death, survival, and the need for ICU admission.

\subsubsection{Secondary Variables}

The secondary variables included the patients' sociodemographic data, previous medical history, clinical outcomes during hospitalization, and the following coagulation parameters recorded at admission and during hospitalization: PT in seconds and \% of plasma dilution (prothrombin activity), 
international normalized ratio (INR), activated partial thromboplastin time (aPTT) with kaolin, aPTT with kaolin ratio, D-dimer, and fibrinogen.

\subsection{Procedures and Statistical Analysis}

All demographic, clinical, laboratory, treatment, and outcome data were extracted from the electronic records of La Paz University Hospital. Quantitative variables were presented using robust statistics, such as mean and interquartile ranges (IQRs), and qualitative data were presented using their frequency distribution. For the comparison of quantitative data between groups, we employed the Kruskal-Wallis non-parametric $\mathrm{H}$ test and the Shapiro-Wilk test for non-normally distributed data. For the comparison of qualitative variables, we employed the chi-squared test. We performed the survival estimates using the Kaplan-Meier method, comparing the survival curves according to the coagulation parameters between the groups using the Wilcoxon test, given that the survival curves did not reach the median survival. We constructed these curves according to the parameters considered in the range of normality by the hospital's laboratory. We performed the multivariate analysis using a Cox regression with the forward conditional method, introducing the coagulation factors as the independent variables. The results of the multivariate model were presented as hazard ratios $(95 \%$ confidence interval $[\mathrm{CI}]$ ) and were graphically represented by a nomogram.

\section{Results}

Of the 3581 study participants, $48.94 \%$ were men, and $19.80 \%$ were healthcare workers. The median age was 62 years (IQR, 47-78). Table 1 lists the patients' demographic and clinical characteristics. In terms of the possible causes of transmission, $17.09 \%$ of the patients reported direct contact with an infected person, while $30.56 \%$ had suspected nosocomial COVID-19 infection.

Table 1. Cohort's Demographic Characteristics.

\begin{tabular}{lc}
\hline \multicolumn{1}{c}{ Characteristic } \\
\hline Sex, $n(\%)$ & $1725(48.94)$ \\
Male & $1800(51.06)$ \\
Female & $62(47-78)$ \\
Median age, years (IQR) & $668(19.80)$ \\
Healthcare workers, $n(\%)$ & \\
Housing, $n$ (\%) & $3163(90.60)$ \\
Uncrowded house conditions & $314(8.99)$ \\
Nursing homes & $13(0.37)$ \\
Shelter residences & $1(0.03)$ \\
Prison & $554(17.09)$ \\
Direct/close contact with a confirmed COVID-19 patient, $n(\%)$ & $1064(30.56)$ \\
Suspected nosocomial transmission, $n(\%)$ & \\
Functional dependence, $n$ (\%) & $252(7.44)$ \\
Dependence in daily activities & $190(5.61)$ \\
Partial dependence in daily activities & $2943(86.94)$ \\
Independence in daily activities & \\
Severity scales, score (range) & $1(0-2)$ \\
CURB 65 & $2(1-4)$ \\
Fine & $0(0-1)$ \\
Q-SOFA & $0(0-1)$ \\
SOFA & $1(0-4)$ \\
PSI & $2178(63.22)$ \\
Oxygen therapy, $n$ (\%) & \\
Delivery methods of oxygen therapy, $n(\%)$ & $178(8.18)$ \\
Venturi mask & $14(0.64)$ \\
Simple face mask & $1170(53.79)$ \\
$\quad$ Nasal cannula/Nasal prongs &
\end{tabular}


Table 1. Cont.

\begin{tabular}{lc}
\hline \multicolumn{1}{c}{ Characteristic } \\
\hline Mask with an oxygen reservoir bag & $567(26.07)$ \\
Non-invasive mechanical ventilation & $109(5.01)$ \\
Invasive mechanical ventilation & $137(6.30)$ \\
Prone position, $n(\%)$ & $188(6.43)$ \\
Positive and expiratory pressure & $10.50(9.50-14.00)$ \\
Inspired positive airway pressure & $18.00(14.00-40.00)$ \\
Respiratory frequency, bpm & $18.00(18.00-20.00)$ \\
ICU admission, $n(\%)$ & $173(5.08)$ \\
\hline
\end{tabular}

Abbreviations: ICU, intensive care unit; IQR, interquartile range; PSI, pneumonia severity index; SOFA, Sepsis-related Organ Failure Assessment; Q-SOFA, quick SOFA.

Upon arrival at the emergency room, $63.22 \%$ of the patients required oxygen therapy, with nasal cannulas the most widely employed oxygen delivery device. Only $5.08 \%$ of the participants required ICU admission at arrival.

Table 2 shows the differences in blood coagulation parameters between the survivors and non-survivors. Despite the normal ranges, the non-survivors had a lower prothrombin activity (82.5-IQR, 67-95) vs. 95.25 (IQR, 87-104); $p<0.001$ ), higher fibrinogen levels (748.5-IQR, 557-960) vs. 572.75 (IQR, 417-758); $p<0.001$ ), and notably higher D-dimer levels (2329 (IQR, 1086.12-5670.40) vs. 635.5 (IQR, 325.5-1194.8); $p<0.001$ ) than the survivors.

Table 2. Blood Coagulation Parameters between Survivors and Non-survivors.

\begin{tabular}{cccc}
\hline & Survivors & Non-Survivors & \\
\cline { 2 - 4 } & $\boldsymbol{n}=\mathbf{2 7 3 1}$ & $\boldsymbol{n}=\mathbf{6 4 2}$ & $\boldsymbol{p}$ \\
\hline Prothrombin activity, \% (IQR) & $95.25(87.00-104.00)$ & $82.5(67.0-95.0)$ & $<0.001$ \\
\hline Fibrinogen, mg/dL (IQR) & $572.75(417.00-758.00)$ & $748.5(557.0-960.8)$ & $<0.001$ \\
\hline INR & $1.0(1.0-1.1)$ & $1.1(1.0-1.2)$ & $<0.001$ \\
\hline Prothrombin time, s (IQR) & $11.0(10.6-11.4)$ & $11.65(11.03-12.70)$ & $<0.001$ \\
\hline D-dimer, ng/mL (IQR) & $635.5(385.5-1194.87)$ & $2329(1086.12-5670.4)$ & $<0.001$ \\
\hline $\begin{array}{c}\text { Partial thromboplastin time with } \\
\text { kaolin, s (IQR) }\end{array}$ & $27.8(26.25-29.60)$ & $29.3(27.0-32.2)$ & $<0.001$ \\
\hline $\begin{array}{c}\text { Activated partial thromboplastin } \\
\text { time ratio with kaolin, s (IQR) }\end{array}$ & $1.04(0.98-1.11)$ & $1.1(1.01-1.21)$ & $<0.001$ \\
\hline
\end{tabular}

Abbreviations: INR, international normalized ratio; IQR, interquartile range.

In terms of ICU admission as a poor prognosis factor, we observed that not all coagulation parameters were statistically different between the patients who were admitted to ICU and those not admitted (Table 3). Only prothrombin activity, PT, and D-dimer levels were associated with ICU admission. Prothrombin activity was lower, and PT was slightly more prolonged in the ICU patients (regardless of the normal ranges of both parameters in both groups), whereas D-dimer levels were remarkably higher among the ICU patients.

Figures 1-6 show the survival curves according to the cut-off points of the coagulation parameters and for D-dimer, as well as the $p$-values based on the Wilcoxon test. A prolonged prothrombin time $(>16 \mathrm{~s})$ was associated with a higher probability of death. Similarly, prolonged aPTT with kaolin $(>40 \mathrm{~s})$ was also associated with a higher mortality rate. 
Table 3. Intensive Care Unit Admissions.

\begin{tabular}{cccc}
\hline Variable & No $(n=3420)$ & Yes $(n=161)$ & $p$ \\
\hline Prothrombin activity, \% (IQR) & $93.5(83.0-103.5)$ & $87.0(76.0-98.0) \%$ & $<0.001$ \\
\hline Fibrinogen, mg/dL (IQR) & $599.8(432.5-788.6)$ & $681.0(423.0-882.0)$ & 0.054 \\
\hline INR, $n$ (IQR) & $1.0(1.0-1.1)$ & $1.1(1.0-1.1)$ & $<0.001$ \\
\hline Prothrombin time, s (IQR) & $11.1(10.7-11.6)$ & $11.4(10.9-12.0)$ & $<0.001$ \\
\hline D-dimer, ng/mL (IQR) & $720.0(410.0-1452.3)$ & $4190.0(2347.12-9735.0)$ & $<0.001$ \\
\hline Functional fibrinogen, mg/dL (IQR) & $101.0(74.8-414.0)$ & $78.5(72.6-88.0)$ & 0.176 \\
\hline $\begin{array}{c}\text { Partial thromboplastin time with } \\
\text { kaolin, s (IQR) }\end{array}$ & $28.0(26.4-30.0)$ & $27.95(26.5-29.8)$ & 0.564 \\
\hline $\begin{array}{c}\text { Activated partial thromboplastin } \\
\text { time ratio with kaolin, mg/dL (IQR) }\end{array}$ & $1.05(0.99-1.12)$ & $1.05(0.99-1.12)$ & 0.592 \\
\hline
\end{tabular}

Abbreviations: INR, international normalized ratio; IQR, interquartile range.

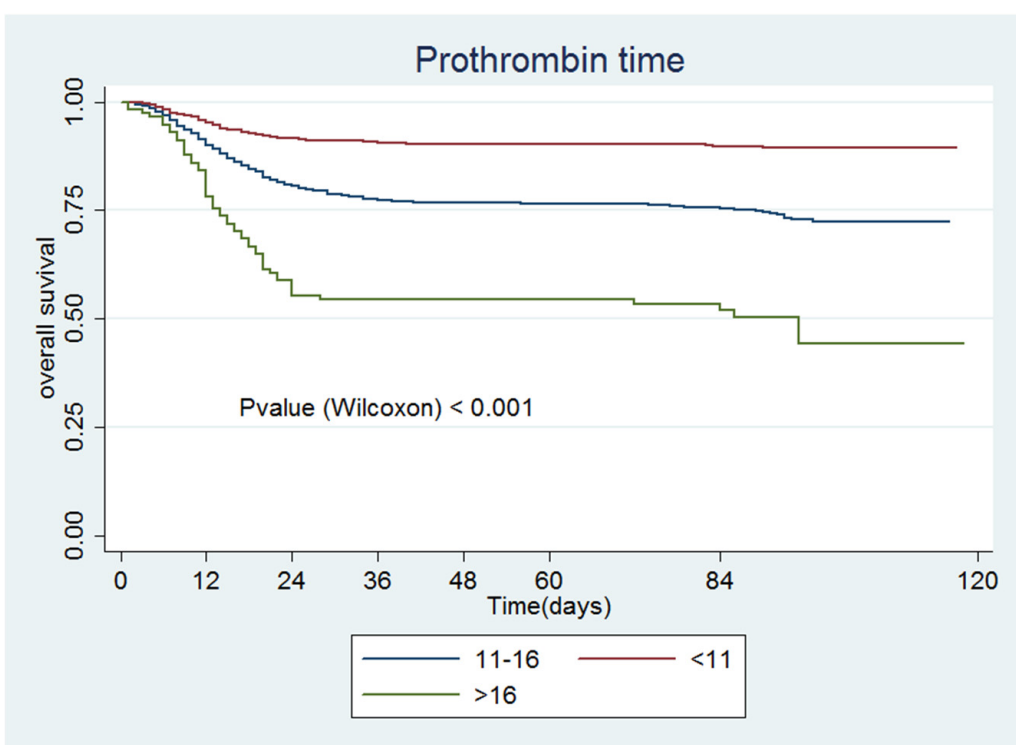

Figure 1. Prothrombin activity.

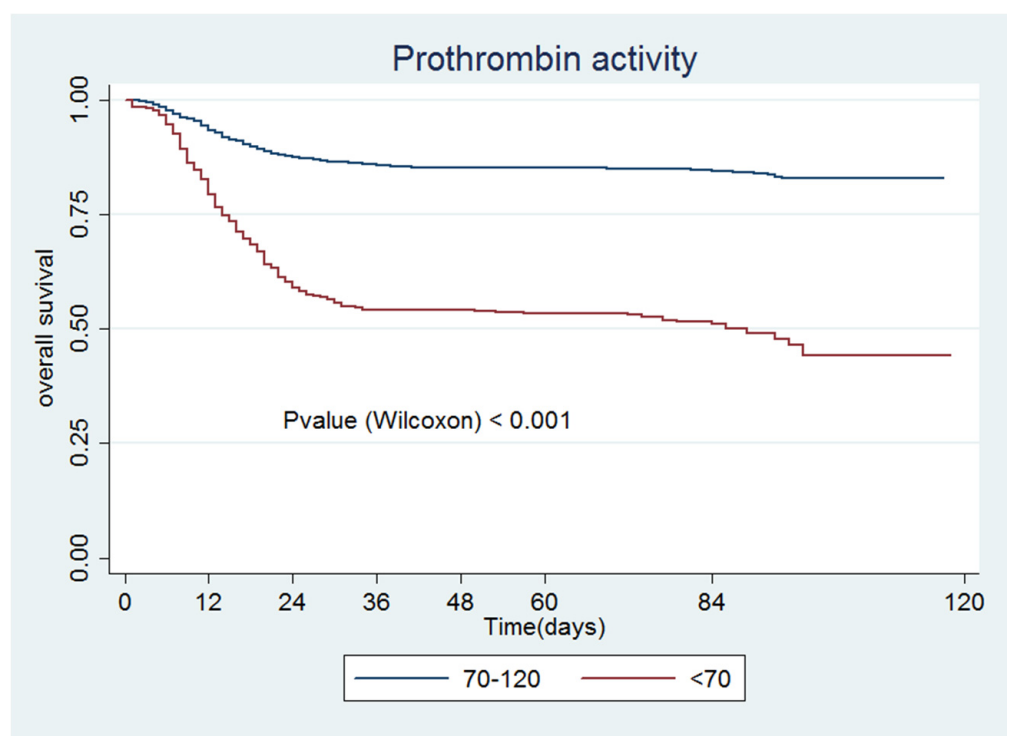

Figure 2. Prothrombin activity. 


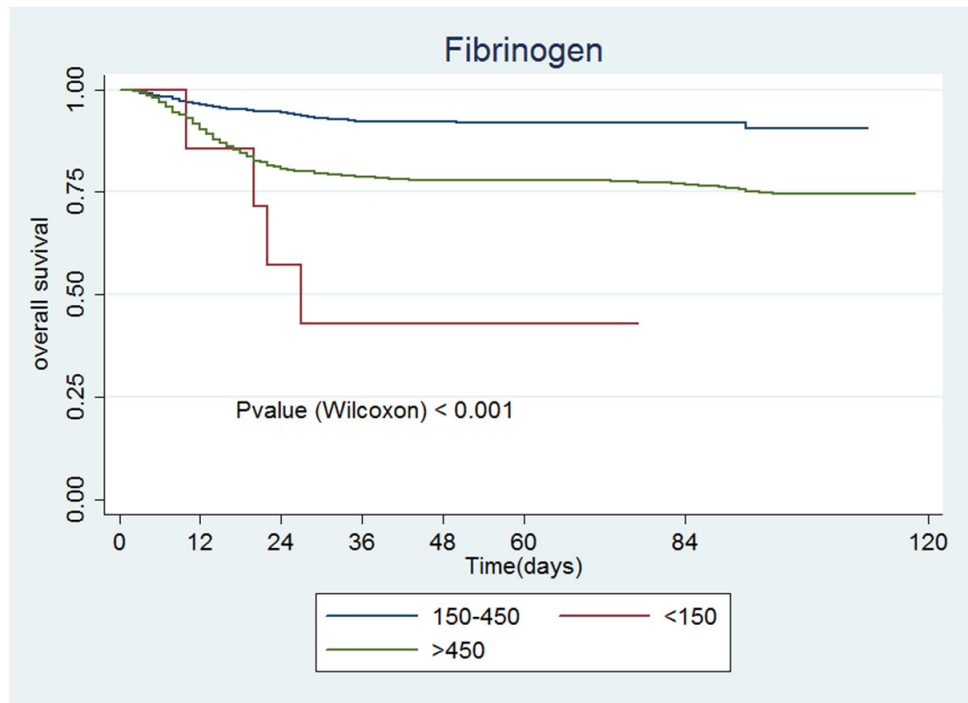

Figure 3. Fibrinogen.

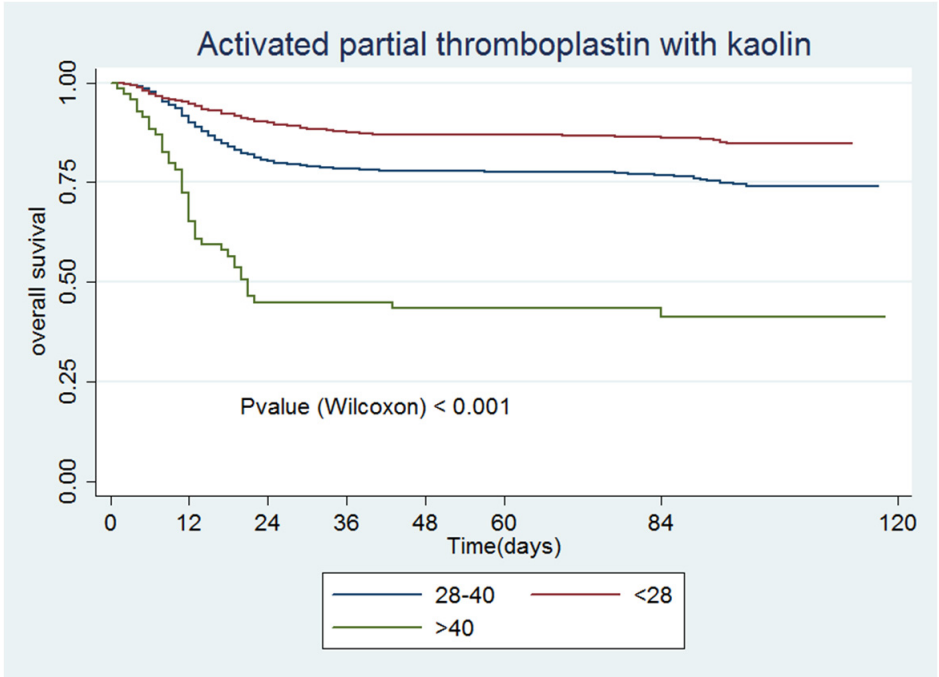

Figure 4. Activated partial thromboplastin time with kaolin.

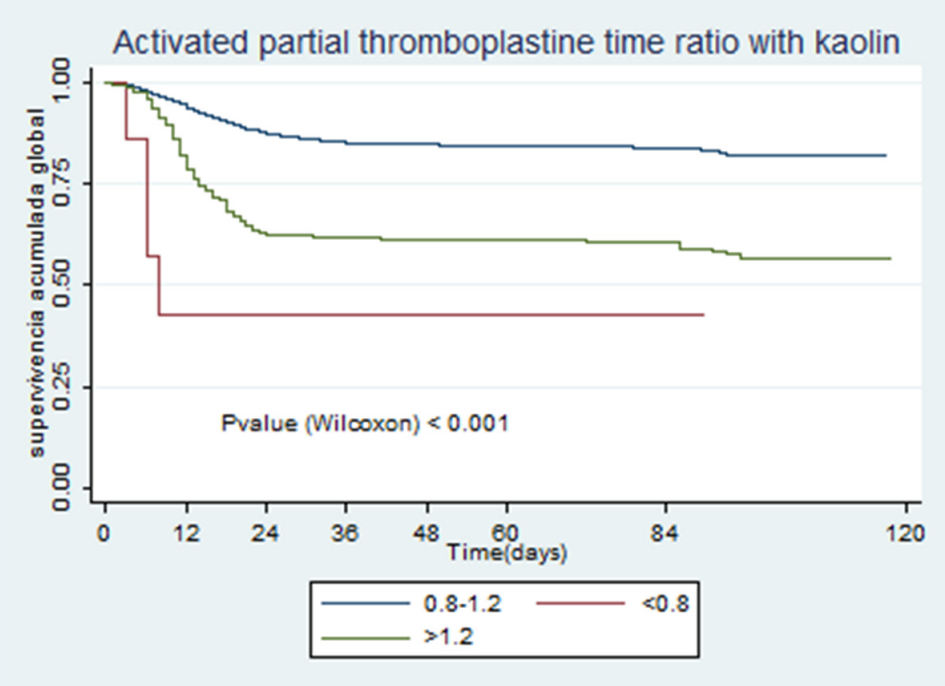

Figure 5. Activated partial thromboplastin time ratio with kaolin. 


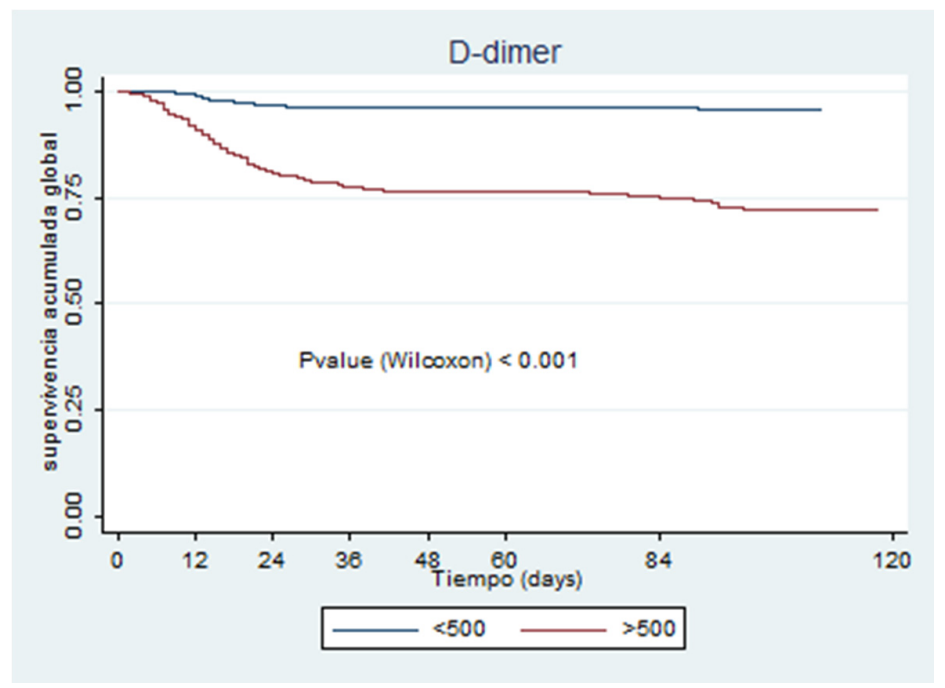

Figure 6. D-dimer.

Table 4 presents the univariate and multivariate Cox models. All of the coagulation parameters were associated with mortality, given that the values were separated from the normal ranges. Only PT values $<11 \mathrm{~s}$ and aPTT with kaolin values $<28 \mathrm{~s}$ were protective against death.

Table 4. Univariate and Multivariate Cox Models.

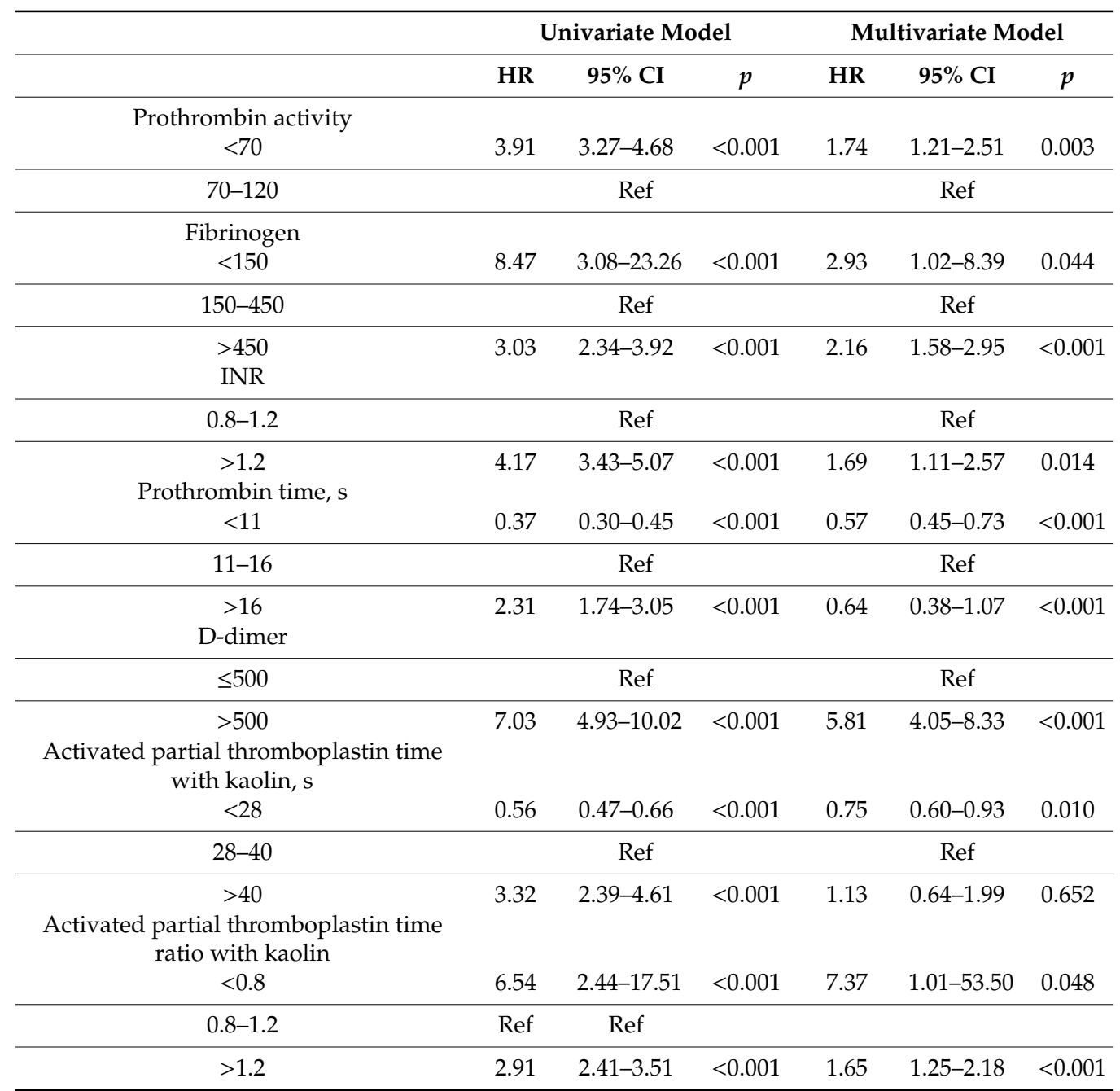

Abbreviations: CI, confidence interval; HR, hazard ratio; INR, international normalized ratio. 
Figure 7 presents the multivariate model in a nomogram that represents the likelihood of death at 15 and 30 days based on a scale from 0 to 40. Using this scale, we could observe a strong association between each of the coagulation parameters and mortality. The figure shows that an aPTT ratio with kaolin $>40$ was already associated with a higher score (with practically 10 out of 40 points), followed by D-dimer with 9 out of 40 points. We could also see that for scores $>25$ points, the 15 -day and 30-day survival rates were approximately $60 \%$ and $38 \%$, respectively.

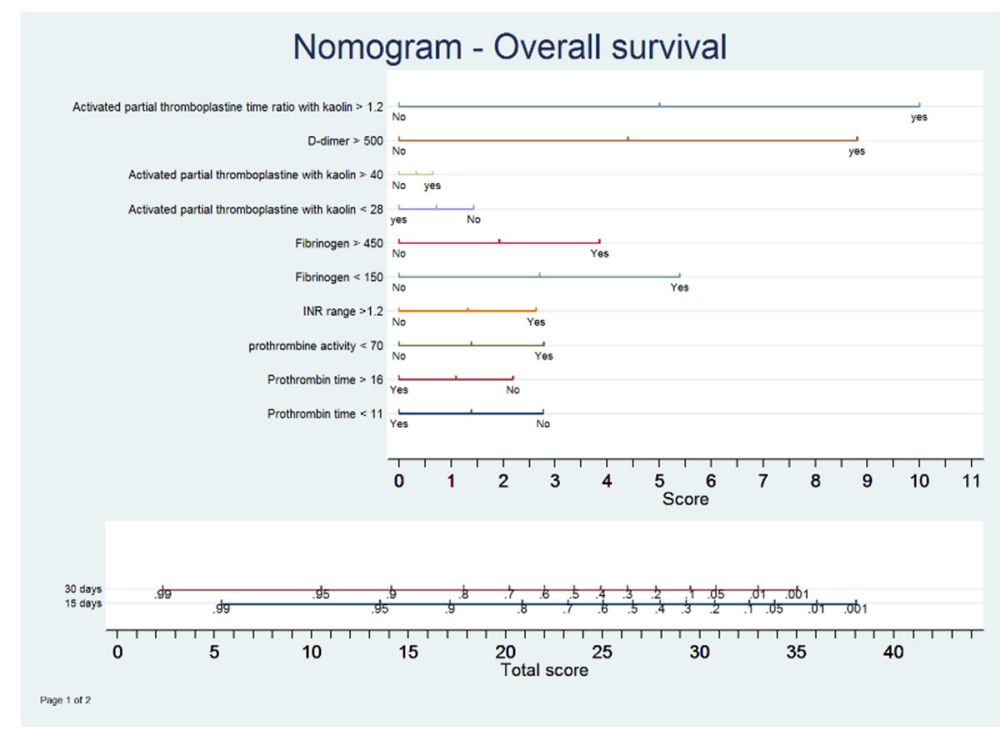

Figure 7. Nomogram.

\section{Discussion}

The aim of this study was to evaluate the relationship between coagulation abnormalities and prognosis (need for ICU admission, survival, and death) in a cohort of 3581 COVID-19 patients from a tertiary reference hospital in Madrid, Spain. Our study's strength was its large sample size and a large number of study variables, which provided confidence in the results, consolidating the knowledge on this study's objective. Although the cumulative differences in the measured parameters were not always striking (some of them moving within the normal range), the figures clearly show that gradual differences in each parameter were associated with mortality (e.g., prothrombin time ratio $<70 \%$, D-dimer levels $>500 \mathrm{ng} / \mathrm{mL}$ ).

From the sociodemographic results, we could see that $19.80 \%$ of the admissions consisted of healthcare workers. Other studies have reported infection rates among professionals of 3-29\%. These findings $[17,18]$ are important considerations due to the current shortage of health professionals for combating the pandemic, which could jeopardize the effectiveness of the health system response and could be exacerbated by the isolation of non-COVID-positive practitioners as preventive measures [19]. This situation also indirectly leads to exhaustion among the other active workers. A recent study suggested that up to $3 \%$ of health workers could be asymptomatically positive, with the consequent risk for other health workers, patients, and the community. For this reason, limiting nosocomial transmission and performing diagnostic tests in the professional field is advisable to better control the disease [20].

The high mortality rate found in our study (approximately 19\%) contrasted with the low ICU admission rate $(5.08 \%)$. During the peak of the pandemic in Spain, a number of patients were declared non-recoverable and, therefore, not eligible for ICU admission, explaining the contrast between the two findings. This situation was not exclusive to Spain; other countries with very high numbers of COVID-19 admissions and with peaks of severe healthcare stress (such as Italy and China) applied similar practices to reduce the stress on the ICU [21]. 
This study's main findings were consistent with the poor prognosis associated with abnormal coagulation parameters in COVID-19 patients indicated by other reports. D-dimer levels were more than 3-fold higher in the ICU patients than in those who did not require ICU admission (4190.0 (2347.12-9735.0) vs. 720.0 (410.0-1452.3); $p<0.001)$. Huang et al. [22] reported 5-fold higher D-dimer levels among ICU patients, demonstrating that D-dimer levels were associated with poorer outcomes. In our study, non-survivors showed a more than 3.5-fold increase in D-dimer levels compared with the survivors (2329-1086.12-5670.4) vs. 635.5 (385.5-1194.87); $p<0.001)$. Wang et al. [23] demonstrated that D-dimer levels in non-survivors reached $>1000 \mathrm{mg} / \mathrm{dL}$ before death. The univariate and multivariate models showed that D-dimer elevation statistically increased the mortality risk (7.03-95\% CI 4.93-10.02) and 5.81 (CI 4.05-8.33); $p<0.001$ ), which was similar to that reported by Yao et al., who found that D-dimer elevation at admission increased the severity of COVID-19 and was related to a high risk of mortality (OR, 10.17; 95\% CI 1.10-94.38; $p=0.041)$ [4]. A recent meta-analysis that included 16 retrospective and 2 prospective studies reported a significant difference in D-dimer levels between survivors and non-survivors, showing an excess risk of up to 4-fold higher in patients with high D-dimer levels, findings that were lower than those of our study. The meta-analysis also concluded that the disease severity was related to medium to high D-dimer levels [24]. In contrast to DIC, which is associated with low platelet counts, elevated D-dimer levels, and low fibrinogen levels, our results supported the assertion that the abnormal coagulation parameters observed in COVID-19 could be different from those in DIC [6]. For instance, our results showed that ICU and non-ICU patients had fibrinogen levels $>450 \mathrm{~g} / \mathrm{dL}$ (681.0 [423.0-882.0] vs. $599.8(432.5-788.6), p=0.054)$, as did the survivors and non-survivors (572.75-417.00-758.00) vs. 748.5 (557.0-960.8), $p<0.001$ ); however, the fibrinogen levels were higher (with statistical significance) among the non-survivors, thereby indicating that the pathophysiological changes behind these levels are mostly driven by inflammation than by consumption, which is why typical DIC as consumption is not a frequent feature of COVID-19.

Based on the patients' medical history and disease progression, it is clear that coagulopathies are frequent events in COVID-19 disease. The extremely high D-dimer levels found in this disease and the high fibrinolytic activity could be due to the body's attempts to eliminate fibrin and necrotic tissue from the lung parenchyma $[25,26]$. Thromboprophylaxis is, therefore, frequently employed to prevent complications, such as deep vein thrombosis and PE. High D-dimer levels $(>1.0 \mu \mathrm{g} / \mathrm{mL})$ have been associated with deep vein thrombosis in patients not admitted to the ICU, despite the administration of thromboprophylaxis, thereby suggesting the need for prospectively considering aggressive doses of heparin [26]. Considering the results of the univariate model, the mortality risk was higher with levels $<150 \mathrm{mg} / \mathrm{dL}(8.47 ; 95 \%$ CI 3.08-23.26; $p<0.001)$, and the Kaplan-Meier curve (Figure 3) showed that patients with lower fibrinogen levels had a lower survival rate.

Our study has a number of limitations. We excluded a number of patients due to incomplete documentation or a lack of laboratory results. However, our study's findings were consistent with those of Tang et al. [14], who analyzed 183 patients with novel coronavirus pneumonia and found higher fibrinogen levels among those who did not survive but had sudden low fibrinogen levels shortly before death. A study similar to ours conducted in China with 113 COVID-19 patients obtained similar results, with elevated fibrinogen and D-dimer levels in critically ill patients [27].

\section{Conclusions}

The increase in coagulation parameters could be an efficient measure for predicting the prognosis and improving the clinical management of patients with COVID-19. D-dimer and fibrinogen levels have been clearly shown as predictors of mortality.

Author Contributions: Conceptualization, M.Q.-D. and E.M.A.-E.; methodology, V.G.-C.; software, E.M.A.-E.; validation, K.L.R.-C.; formal analysis, R.J.-V.; investigation, E.M.A.-E.; resources, B.O.-B.; data curation, V.G.-C.; writing and original draft preparation, B.O.-B.; writing, review, and editing, R.J.-V.; visualization, E.M.A.-E.; supervision, M.Q.-D.; project administration, V.G.-C. All authors have read and agreed to the published version of the manuscript. 
Funding: This research received funding from ISCIII, Code: COV20/00519.

Acknowledgments: COVID@HULP Working Group of Hospital La Paz and to Silvia Arce and Raquel Carmona.

Conflicts of Interest: The authors declare no conflict of interest.

\section{References}

1. Novel Coronavirus-China World Health Organization. Available online: https://www.who.int/csr/don/12january-2020-novel-coronavirus-china/en/ (accessed on 25 September 2020).

2. Coronavirus Outbreak. Available online: https://www.worldometers.info/coronavirus/ (accessed on 25 September 2020).

3. Gupta, A.; Madhavan, M.V.; Sehgal, K.; Nair, N.; Mahajan, S.; Sehrawat, T.S.; Bikdeli, B.; Ahluwalia, N.; Ausiello, J.C.; Wan, E.Y.; et al. Extrapulmonary manifestations of COVID-19. Nat. Med. 2020, 26, 1017-1032. [CrossRef] [PubMed]

4. Yao, Y.; Cao, J.; Wang, Q.; Shi, Q.; Liu, K.; Luo, Z.; Chen, X.; Chen, S.; Yu, K.; Huang, Z.; et al. D-dimer as a biomarker for disease severity and mortality in COVID-19 patients: A case control study. J. Intensive Care 2020, 8, 1-11. [CrossRef] [PubMed]

5. Tang, N.; Li, D.; Wang, X.; Sun, Z. Abnormal coagulation parameters are associated with poor prognosis in patients with novel coronavirus pneumonia. J. Thromb. Haemost. 2020, 18, 844-847. [CrossRef] [PubMed]

6. Panigada, M.; Bottino, N.; Tagliabue, P.; Grasselli, G.; Novembrino, C.; Chantarangkul, V.; Pesenti, A.; Peyvandi, F.; Tripodi, A. Hypercoagulability of COVID-19 patients in intensive care unit: A report of thromboelastography findings and other parameters of hemostasis. J. Thromb. Haemost. 2020, 18, 1738-1742. [CrossRef]

7. Levi, M.; Thachil, J.; Iba, T.; Levy, J.H. Coagulation abnormalities and thrombosis in patients with COVID-19. Lancet Haematol. 2020, 7, e438-e440. [CrossRef]

8. Adam, E.; Zacharowski, K.; Miesbach, W. A comprehensive assessment of the coagulation profile in critically ill COVID-19 patients. Thromb. Res. 2020, 194, 42-44. [CrossRef]

9. Violi, F.; Pastori, D.; Cangemi, R.; Pignatelli, P.; Loffredo, L. Hypercoagulation and Antithrombotic Treatment in Coronavirus 2019: A New Challenge. Thromb. Haemost. 2020, 120, 949-956. [CrossRef]

10. Zhai, Z.; Li, C.; Chen, Y.; Gerotziafas, G.; Zhang, Z.; Wan, J.; Liu, P.; Elalamy, I.; Wang, C. Prevention and Treatment of Venous Thromboembolism Associated with Coronavirus Disease 2019 Infection: A Consensus Statement before Guidelines. Thromb. Haemost. 2020, 120, 937-948. [CrossRef]

11. Poissy, J.; Goutay, J.; Caplan, M.; Parmentier, E.; Duburcq, T.; Lassalle, F.; Jeanpierre, E.; Rauch, A.; Labreuche, J.; Susen, S.; et al. Pulmonary Embolism in Patients with COVID-19. Circulation 2020, 142, 184-186. [CrossRef]

12. Abou-Ismail, M.Y.; Diamond, A.; Kapoor, S.; Arafah, Y.; Nayak, L. The hypercoagulable state in COVID-19: Incidence, pathophysiology, and management. Thromb. Res. 2020, 194, 101-115. [CrossRef]

13. Gustafson, D.; Raju, S.; Wu, R.; Ching, C.; Veitch, S.; Rathnakumar, K.; Boudreau, E.; Howe, K.L.; Fish, J.E. Overcoming Barriers: The Endothelium as a Linchpin of Coronavirus Disease 2019 Pathogenesis? Arterioscler. Thromb. Vasc. Biol. 2020, 40, 1818-1829. [CrossRef] [PubMed]

14. Tang, N.; Bai, H.; Chen, X.; Gong, J.; Li, D.; Sun, Z. Anticoagulant treatment is associated with decreased mortality in severe coronavirus disease 2019 patients with coagulopathy. J. Thromb. Haemost. 2020, 18, 1094-1099. [CrossRef] [PubMed]

15. Helms, J.; Tacquard, C.; Severac, F.; Leonard-Lorant, I.; Ohana, M.; Delabranche, X.; Merdji, H.; Clere-Jehl, R.; Schenck, M.; Gandet, F.F.; et al. High risk of thrombosis in patients with severe SARS-CoV-2 infection: A multicenter prospective cohort study. Intensive Care Med. 2020, 46, 1089-1098. [CrossRef] [PubMed]

16. Klok, F.; Kruip, M.; Van Der Meer, N.; Arbous, M.; Gommers, D.; Kant, K.; Kaptein, F.; Van Paassen, J.; Stals, M.; Huisman, M.; et al. Confirmation of the high cumulative incidence of thrombotic complications in critically ill ICU patients with COVID-19: An updated analysis. Thromb. Res. 2020, 191, 148-150. [CrossRef] [PubMed]

17. Wu, Z.; McGoogan, J.M. Characteristics of and important lessons from the coronavirus disease 2019 (COVID-19) outbreak in China: Summary of a report of 72,314 cases from the Chinese Center for Disease Control and Prevention. JAMA J. Am. Med. Assoc. 2020, 323, 1239-1242. [CrossRef] 
18. Wong, S.-Y.; Kwong, R.-S.; Wu, T.; Chan, J.; Chu, M.; Lee, S.; Wong, H.; Lung, D. Risk of nosocomial transmission of coronavirus disease 2019: An experience in a general ward setting in Hong Kong. J. Hosp. Infect. 2020, 105, 119-127. [CrossRef] [PubMed]

19. Rivett, L.; Sridhar, S.; Sparkes, D.; Routledge, M.; Jones, N.K.; Forrest, S.; Young, J.; Pereira-Dias, J.; Hamilton, W.L.; Ferris, M.; et al. Screening of healthcare workers for SARS-CoV-2 highlights the role of asymptomatic carriage in COVID-19 transmission. eLife 2020, 9. [CrossRef] [PubMed]

20. Black, J.R.M.; Bailey, C.; Przewrocka, J.; Dijkstra, K.K.; Swanton, C. COVID-19: The case for health-care worker screening to prevent hospital transmission. Lancet 2020, 395, 1418-1420. [CrossRef]

21. Boreskie, K.F.; Boreskie, P.E.; Melady, D. Age is just a number-And so is frailty: Strategies to inform resource allocation during the COVID-19 pandemic. Can. J. Emerg. Med. 2020, 22, 411-413. [CrossRef]

22. Huang, C.; Wang, Y.; Li, X.; Ren, L.; Zhao, J.; Hu, Y.; Zhang, L.; Fan, G.; Xu, J.; Gu, X.; et al. Clinical features of patients infected with 2019 novel coronavirus in Wuhan, China. Lancet 2020, 395, 497-506. [CrossRef]

23. Wang, D.; Hu, B.; Hu, C.; Zhu, F.; Liu, X.; Zhang, J.; Wang, B.; Xiang, H.; Cheng, Z.; Xiong, Y.; et al. Clinical Characteristics of 138 Hospitalized Patients with 2019 Novel Coronavirus-Infected Pneumonia in Wuhan, China. JAMA 2020, 323, 1061. [CrossRef]

24. Shah, S.; Shah, K.; Patel, S.B.; Patel, F.S.; Osman, M.; Velagapudi, P.; Turagam, M.K.; Lakkireddy, D.; Garg, J. Elevated D-Dimer Levels are Associated with Increased Risk of Mortality in COVID-19. Cardiol. Rev. 2020. [CrossRef]

25. Artifoni, M.; Danic, G.; Gautier, G.; Gicquel, P.; Boutoille, D.; Raffi, F.; Néel, A.; LeComte, R. Systematic assessment of venous thromboembolism in COVID-19 patients receiving thromboprophylaxis: Incidence and role of D-dimer as predictive factors. J. Thromb. Thrombolysis 2020, 50, 211-216. [CrossRef] [PubMed]

26. Medcalf, R.L.; Keragala, C.B.; Myles, P.S. Fibrinolysis and COVID-19: A plasmin paradox. J. Thromb. Haemost. 2020, 18, 2118-2122. [CrossRef]

27. Bi, X.; Su, Z.; Yan, H.; Du, J.; Wang, J.; Chen, L.; Peng, M.; Chen, S.; Shen, B.; Li, J. Prediction of severe illness due to COVID-19 based on an analysis of initial Fibrinogen to Albumin Ratio and Platelet count. Platelets 2020, 31, 674-679. [CrossRef] [PubMed]

Publisher's Note: MDPI stays neutral with regard to jurisdictional claims in published maps and institutional affiliations.

(C) 2020 by the authors. Licensee MDPI, Basel, Switzerland. This article is an open access article distributed under the terms and conditions of the Creative Commons Attribution (CC BY) license (http://creativecommons.org/licenses/by/4.0/). 